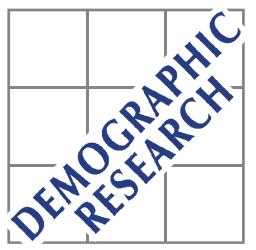

Demographic Research a free, expedited, online journal of peer-reviewed research and commentary in the population sciences published by the Max Planck Institute for Demographic Research Konrad-Zuse Str. 1, D-18057 Rostock · GERMANY www.demographic-research.org

DEMOGRAPHIC RESEARCH

SPECIAL COLLECTION 2, ARTICLE 13

PUBLISHED 16 APRIL 2004, PAGES 331-354

www.demographic-research.org/special/2/13/

DOI: $10.4054 /$ DemRes.2004.S2.13

Research Article

\title{
Socio-economic inequalities in mortality and health in the developing world
}

\author{
Alberto Minujin \\ Enrique Delamonica
}

The papers in this special collection were presented at the seminar "Determinants of Diverging Trends in Mortality", held at MPIDR, Rostock on 19-21 of June, 2002. The seminar was organized by the Max Planck Institute for Demographic Research and the Committee on Emerging Health Threats of the International Union for the Scientific Study of Population.

(C) 2004 Max-Planck-Gesellschaft. 


\section{Table of Contents}

1 Introduction $\quad 332$

2 A few remarks on methodology and data sources 332

2.1 Describing inequalities 332

2.2 Describing changes in inequality 333

$2.3 \quad$ Inequality trends and absolute levels $\quad 334$

$2.4 \quad$ Remarks on the data used 335

3 Who improved their survival conditions? The 336 achievement of the infant mortality goals and disparities

$4 \quad$ Further considerations 341

5 Immunisation 342

6 Nutrition 345

$7 \quad$ Some comparisons $\quad 347$

$\begin{array}{lll}8 & \text { Conclusions } & 348\end{array}$

9 Acknowledgements 348

$\begin{array}{ll}\text { Notes } & 350\end{array}$

$\begin{array}{ll}\text { Bibliography } & 352\end{array}$

$\begin{array}{ll}\text { Annex } & 354\end{array}$ 


\title{
Socio-economic inequalities in mortality and health in the developing world
}

\author{
Alberto Minujin ${ }^{1}$ \\ Enrique Delamonica ${ }^{1}$
}

\begin{abstract}
Trends in child mortality disparities show that within country inequities have remained constant in some countries and worsened in most of the other ones. Only three countries, with relatively small populations which comprise less than 2 per cent of our sample, were able to achieve both a reduction in disparity and improvements (or no decline) in national average U5MR. The evolution of nutrition and DPT3 immunisation seems more promising.
\end{abstract}




\section{Introduction}

It is common knowledge that child mortality among the poor is higher than among the rich but until recently it was not possible to find out how wide this gap was, or its relation with the level of child mortality. Even less is known about whether these differences are increasing or declining. The main difficulty is the lack of comparable data.

The objective of this paper is to analyse recent trends in child mortality disparity, using the indicator under five-mortality rate (U5MR) for different wealth groups. It is a descriptive paper that looks at differences on child mortality for different wealth groups across countries and through time. The choice of countries is based on the availability of comparable data for at least two rounds of Demographic and Health Surveys (DHS) (Note 1). Thus, 24 countries were analysed. We studied the trends during the 1990s in infant and child mortality according to the wealth ranking of households. We also contrast this evolution to that of two major determinants of infant and child mortality: malnutrition and immunisation.

The structure of the paper is as follows. There is a section on methodology and data sources (section 2) followed by a description of U5MR trends (sections 3 and 4). Sections 5 and 6 deal respectively with immunisation and nutrition. Some comparisons are offered in section 7 , and section 8 concludes.

\section{A few remarks on methodology and data sources}

\subsection{Describing inequalities}

There are many reasons that make the analysis of disparities relevant. One is that there seems to be increasingly available evidence about growing inequity between and within countries in terms of income (Cornia, 1999). Whether there is a similar pattern in terms of outcome indicators naturally poses itself as a question. Another important reason is that averages are often not very helpful in evaluating social trends. Averages are used to simplify complex realities in an easily interpretable summary measure. However, sometimes they simplify too much. Changes in averages through time, which can be interpreted as "positive", e.g. reduction in U5MR, can occur with similar improvements for all members of society, or they can be the result of improvements of only a few members (Note 2).

The analysis of disparities can be done using different dimensions such as: rich/poor, urban/rural, women/men, ethno-linguistic groups, etc (Atkinson, 1983, Sen 
1997). In this paper we concentrate on a classification of households based on their wealth - lack of space prevents us from looking at all the important dimensions of social disparities. An "asset index" using the presence in the household of certain durable goods (such as a radio or a bicycle), the quality of the dwelling (e.g. roof and floor materials), and access to different types of water and sanitation was constructed following the procedure described by Filmer and Pritchett (1998 a and b) and Gwatkin et al.(1999). A weighted average of these "asset" variables (a list can be found in the annex) is constructed. The weights are arrived at using principal components analysis instead of relying on equal weights for all variables or other ad hoc assumptions. This weighted average can be interpreted as an "asset index" which can then be used to classify households into quintiles (Note 3).

Gini, Theil and Concentration Indices as well as shares of different percentiles are usually used to analyse income and other distributions (Note 4). In this paper we only look at the ratio between U5MR at the bottom and top quintiles. We choose this measure, which we label the "relative gap", because it is easy to interpret. Also we want to use only one measurement in order not to clutter the exposition across countries and across time periods. We have used other measures to check the robustness of our results. For instance, we also looked at the complement of U5MR, i.e. the likelihood of surviving, as suggested in Micklewright and Stewart (2000).

\subsection{Describing changes in inequality}

Alternative methods to compare the results of Demographic and Health Surveys (DHS) through time were attempted and evaluated. One possibility is, for each of the available years, to use a different set of asset indicators. This is due to the fact that the survey questionnaires have evolved through their various applications. As a result, for each year, all the information on assets available in the surveys is used. However, the basis of the classification of households is different, amplifying and confusing the source of the observed variations. Alternatively, the set of common asset indicators in the latest round could be used. However, not all those asset indicators were included in earlier versions of DHS. This loss is (partly) compensated by the better comparability of different rounds of the survey.

We decided to maximize comparability through time by using always the same assets. This requires that the common assets be the ones found in all DHS rounds (three or four in some cases, going as far back as the mid-1980s). This, of course, implies some loss of information (efficiency) in the estimates. It is important to measure this loss empirically, but it seems that the benefits in terms of comparability and length of period under analysis compensate this loss. We tested this by looking at the effect of 
deleting a few asset indicators from the construction of the wealth index. The rank correlation of households using all or some sub-sets of the available assets averaged above 0.9. In other words, we ranked households using the wealth index using all available information; then we ranked the households again but using the wealth index with the smaller set of indicators (i.e. the ones common to both periods). There was very little difference in the rankings.

Furthermore, not only can the same asset indicators be used, but also the same cutoff points for the index can be used. This allows for changes in the size of the groups. In other words, the cut-off values in an earlier DHS separates the households in quintiles of equal size. Applying the same cut-off points to a later survey, results in five household groupings which are not of equal size. Some of the families in the bottom quintile may possess assets allowing them to enjoy amenities which would have made them to be considered "middle class" in the earlier round. This shift in the population from one "quintile" to the other is an indirect measure of increasing income/wealth and can be associated to the idea of a fixed poverty line (Note 5). However, for the purposes of measuring inequality it seems more advisable to maintain groupings of equal size in each point in time. Also, as the surveys are not panel data, there might be additional variance.

\subsection{Inequality trends and absolute levels}

Another issue of importance to highlight is that the relationship between changes in averages and in relative gaps is not a simple one. A modification in the average could correspond to different changes in the distribution and in the relative gap. Changes in averages do not imply any particular modification in disparity.

For example, an improvement on U5MR could go together with increases in the relative gap and could be accompanied by stagnation or deterioration among the disadvantaged and vulnerable children. If we want to take into account not only what happens with the relative gap but also what happens with the poor when both averages and relative gaps widen or narrow, there are many combinations. Not all of the alternatives are relevant or probable to happen. There are four alternative scenarios as can be observed in Table 1 . 
Demographic Research - Special Collection 2: Article 13

-- Determinants of Diverging Trends in Mortality --

Table 1: Possible relationships between changes in averages and disparity indicators

\begin{tabular}{llll}
\hline Trends & \multicolumn{2}{c}{ RELATIVE GAP } \\
\hline AVERAGE & Improving & \multicolumn{1}{c}{ Widening } \\
\hline & West OUTCOME & $\begin{array}{l}\text { "Improvement with } \\
\text { inequity": Improvement for } \\
\text { better-off, but not for } \\
\text { disadvantaged }\end{array}$ \\
& Worsening & $\begin{array}{l}\text { "Worsening with protection": } \\
\text { Worsening with an element of } \\
\text { protection of the disadvantaged }\end{array}$ & WORST OUTCOME \\
\hline
\end{tabular}

This $2 \times 2$ classification based on average results and the relative gap between the top and bottom quintiles, however, may need some further subdivision. This results from the fact that the ratios, or relative performance, expressed in the relative gap, may fail to capture the different possibilities of outcomes among the bottom 20 per cent. For instance, "improvement with inequity" may be the result of a situation where the top 20 per cent gain much more than the bottom 20 per cent. Thus, the average improves while the relative gap widens. It may also be the case that the situation of the bottom 20 per cent deteriorates, but the overall average still improves, pulled by the gains among the top 20 per cent. Given that we are not only interested in inequity but the actual outcome among the worse off, the "improvement with inequity" case may not capture all the information we need.

\subsection{Remarks on the data used}

Before moving to the presentation of the descriptive analysis of the variables and the tables with disaggregated data it is necessary to make a few comments on the source of information selected and how it was used.

First, we chose as source of information the Demographic Health Surveys (DHS) because it provides a set of data which is comparable through countries and over time. Given the kind of information that we wanted to generate, on disparities and trend on disparities, what was needed was data on relevant health outcomes that could be disaggregated among groups (wealth, urban-rural, gender) and available for more than one point in time. Definition of the variables and categories should be the same over time. The DHS cover these requirements. Moreover, that source is compatible with the 
Multiple Indicators Survey (MICS) supported by UNICEF. The results of these surveys will be added in the future and compared with those from DHS to extend the timeseries.

Second, the focus of the project was on disaggregated results and changes over time, not on the estimation of the overall country average. Thus, a key aspect is to ensure the comparability over time of the disaggregated data. This aspect was carefully taken care of, in particular when the methodology for the wealth group, the "asset index" was chosen and applied. In terms of country averages, more accurate and recent information could be found in different UN reports, like the State of the World's Children prepared by UNICEF (Note 6).

Third, depending on the country, the first round of the DHS corresponds to the 1980s and the third or second to the late 1990s. In a few cases the latest available data correspond to the mid 1990s.

Fourth, the years of the DHS's rounds were different in each country. They were assembled for the analysis into periods. When the survey information was downloaded, three DHS rounds were available only for a few countries. Thus, the data was grouped, in most of the cases, in two periods. Except for U5MR, the first period corresponds to the early 1990s (1991-1993) and the second one to the late 1990s (1997-1999). In the case of U5MR, because of the calculation method, the data should be placed some five years before the data survey. The length of time between surveys was 4 or 5 years. Given that each period correspond to a group of years, it is possible that some time effects could be mixed. We attempt to test for this effect in the U5MR trends in section 4 below.

\section{Who improved their survival conditions? The achievement of the infant mortality goals and disparities}

Thanks to the work carried out by Gwatkin et al (1999), it is now possible to gauge the level of inequality in U5MR. Before, it was not known, ex ante, what U5MR differential could be considered "normal" and what is typical of a very unequal society (Note 7). In the case of wealth disparities, the relative gap between the bottom and top quintile (i.e. the U5MR of the bottom quintile according to the "asset index" divided by the U5MR of the top quintile) averages 2.2, and ranges from 1.3 to 4.7. For one third of the countries the relative gap is higher than 2.5. This implies that more than 3 children from families at the bottom of the distribution die for each child who dies among families at the top of the distribution. The question that interests us in this paper, however, relates to changes in disparities. 
In global terms, the estimated changes in U5MR over the period 1990 to 2000 show that the world average fell from 94 per 1000 live births to 81, a decrease of 14\% (Note 8). There are different ways of achieving this reduction of the national average goal. One way, labelled the "top down" approach, improves the situation of the betteroff first. Alternatively, the same reduction in the national average can be achieved by reducing U5MR among the poorest, a "bottom up" approach. In both cases the country could achieve the same level of U5MR but the results in terms of the distribution within the population are fundamentally different (Gwatkin 2000). Nevertheless, the results in terms of relative gaps are basically unknown and the little information available shows an increase in relative gaps for some countries (Sahn et al., 1999; Stecklov G et al, 1999).

A plausible methodology to study trends is to use a regression model to explain U5MR (Note 9). However, this requires a theoretical model which would indicate which variables to include (e.g. access to health, level of education of the mother, access to water, hygiene knowledge, etc). In its absence we merely regressed U5MR on the quintiles and a dummy variable to indicate the DHS round (period) (Note 10). However, this model had poor predictive powers (Note 11). This is a modelling, not a data or statistical problem. We had to use a different approach.

Instead of using econometric techniques, we opted for a more direct statistical analysis. As we had two independent observations of the relative gap (one for each DHS round) for each quintile, we could simply test if they were different. The problem, then, becomes one of constructing a test of differences in ratios, which requires the estimation of covariances, which we did not have. As an alternative, we looked at the components of the ratios, i.e. U5MR in the top and bottom quintile. If, for a given quintile, the two observations are not statistically different, then we could conclude there was no change through time for that quintile (Note 12).

When using this test of differences, we can classify countries according to the pattern which leads to the increase in disparity (Note 13). In the following table, this test is applied to the 18 countries where disparity seems to have increased. If both the bottom quintile (Q1) and the top one (Q5) show constant U5MR results, obviously there is no change in the relative gap. If U5MR for the poorest quintile (Q1) is constant and decreases for the wealthiest quintile (Q5), then disparity increased. If U5MR for both Q1 and Q5 moved in the same direction, whether disparity increased or decreased depends on the relative rate of change in each quintile. 
Demographic Research - Special Collection 2: Article 13

-- Determinants of Diverging Trends in Mortality --

Table 2: $\quad$ Countries where disparity increased between mid/late 1980s and mid/late 1990 s, according to result of $t$-test by quintile*

\begin{tabular}{|c|c|c|c|c|}
\hline $\begin{array}{l}\text { Q1 constant } \\
\text { Q5 decreased }\end{array}$ & $\begin{array}{l}\text { Q1 increased } \\
\text { Q5 constant or } \\
\text { decreased }\end{array}$ & $\begin{array}{l}\text { Q1 decreased } \\
\text { Q5 decreased }\end{array}$ & $\begin{array}{l}\text { Q1 increased } \\
\text { Q5 increased }\end{array}$ & $\begin{array}{l}\text { Q1 constant } \\
\text { Q5 constant }\end{array}$ \\
\hline $\begin{array}{l}\text { Increased } \\
\text { disparity } \\
\text { Bangladesh } \\
\text { Colombia } \\
\text { Dominican Rep. } \\
\text { Indonesia } \\
\text { Philippines } \\
\text { Uganda }\end{array}$ & $\begin{array}{l}\text { Increased } \\
\text { disparity } \\
\text { Kazakhstan } \\
\text { Zimbabwe }\end{array}$ & $\begin{array}{l}\text { Unclear trend in } \\
\text { disparity } \\
\text { Bolivia } \\
\text { Brazil } \\
\text { Ghana } \\
\text { Tanzania }\end{array}$ & $\begin{array}{l}\text { Unclear trend in } \\
\text { disparity }\end{array}$ & $\begin{array}{l}\text { Constant } \\
\text { disparity } \\
\text { Burkina Faso } \\
\text { Cameroon } \\
\text { Egypt } \\
\text { Mali } \\
\text { Peru } \\
\text { Senegal }\end{array}$ \\
\hline
\end{tabular}

Most of the disparity increases are due to situations where the U5MR of the bottom quintile is stagnant or actually worsens. The cases where both quintiles enjoy reductions in U5MR but the top one benefits more seems to have been less common. Unfortunately, this table cannot help us find out if the relative gap increased in this case, i.e. when differences are significant for both quintiles, even if the percentage reduction are almost twice as large for the top than for the bottom quintiles (Note 14). For these four countries, we estimated a different set of hypotheses.

In all four countries, the U5MR relative reduction in the top quintile is almost twice as large as in the bottom one. This, by itself, could be considered grounds to assert that there is an increase in disparity. However, it is not enough. We need to test if the changes are of the same magnitude. We did this by testing the one-tailed hypotheses that U5MR was reduced by 50\% (i.e. in the first period U5MR was double the level in the second period) for each quintile. We also tested if the decline was $25 \%$. The results are reported in the following table. 
Table 3: $\quad$ U5MR reduction by quintile (\%) between mid/late 1980s and mid/late 1990s for countries where both Q1 and Q5 show statistically significant changes

\begin{tabular}{|c|c|c|c|c|}
\hline & \multicolumn{2}{|c|}{ Q1 } & \multicolumn{2}{|c|}{ Q5 } \\
\hline & $50 \%$ decrease & $25 \%$ decrease & $50 \%$ decrease & $25 \%$ decrease \\
\hline Bolivia & Rejected & Rejected & $\sqrt{ }$ & $\sqrt{ }$ \\
\hline Brazil & Rejected & Rejected & $\sqrt{ }$ & $\sqrt{ }$ \\
\hline Ghana & Rejected & Rejected & Rejected & $\sqrt{ }$ \\
\hline Tanzania & Rejected & Rejected & $\sqrt{ }$ & $\sqrt{ }$ \\
\hline
\end{tabular}

Source: Based on DHS data

It can be observed that although the hypothesis of no change had been rejected for the poorest quintile in these four countries, that change was not very large as both the hypotheses of 50\% and 25\% reduction are rejected. For Bolivia, Brazil and Tanzania, the hypothesis of 50\% reduction in U5MR for the richest households is not rejected (the checkmarks in the table). A 50\% reduction in U5MR for the richest groups, when the poorest groups do not even achieve a reduction of $25 \%$, clearly indicates an increase in disparity. In Ghana, where only the $25 \%$ reduction was not rejected for the top quintile, the same conclusion still applies.

Table 4, below, presents similar information to Table 2 but for the countries where the relative gap seems to have declined. As in the case where the relative gap seems to increase, not all cases are statistically significant. Nevertheless, Guatemala, Togo and Zambia show significant changes. Morocco, which presents significant U5MR reductions for both the top and bottom quintiles according to the t-test, is a bit of an ambiguous case. However, the reduction for both quintiles is of about a third and setting hypotheses tests for reductions of $50 \%$ and $25 \%$ (similar to the ones reported in Table 3 ) indicates that there has not been a significant reduction in disparity. 
Demographic Research - Special Collection 2: Article 13

-- Determinants of Diverging Trends in Mortality --

Table 4: $\quad$ Countries where disparity decreased between mid/late 1980s and mid/late 1990s, according to result of $t$-test by quintile*

\begin{tabular}{ccccc}
\hline Q1 decreased & Q1 constant & Q1 decreased & Q1 increased & Q1 constant \\
Q5 constant & Q5 increased & Q5 decreased & Q5 increased & Q5 constant \\
\hline Lower disparity & Lower disparity & Unclear trend in & Unclear trend in & Constant \\
& & disparity & disparity & disparity \\
Guatemala & Zambia & Morocco & & Kenya \\
Togo & & & Niger \\
\hline
\end{tabular}

Notes:

* "Q $Q_{i}$ constant" means that the null hypothesis U5MR $Q_{i} t 0=$ U5MR $Q_{i} t 1$ was not rejected. See table 2.

Source: Based on DHS data

In terms of the classification proposed in section 2, the table below shows, for 24 countries, both the changes in the average level of U5MR and the changes in relative gap. These trends in child mortality disparities show that within country inequities have remained constant in some countries and worsened in most of the other ones. Only three countries, with relatively small populations which comprise less than 2 per cent of our sample, were able to achieve both a reduction in disparity and improvements (or at least no decline) in average.

Table 5: $\quad$ Changes in average U5MR and relative gap, 1980s and 1990s, selected countries.

\begin{tabular}{|c|c|c|c|c|}
\hline \multirow[t]{2}{*}{ Trends } & & \multicolumn{3}{|c|}{ RELATIVE GAP } \\
\hline & & Narrowing & Constant & Widening \\
\hline & Improving & Guatemala & Egypt & Bangladesh \\
\hline & & & Mali & Bolivia \\
\hline \multirow[t]{9}{*}{ AVERAGE } & & & Morocco & Brazil \\
\hline & & & Peru & Colombia \\
\hline & & & Senegal & Dominican Rep. \\
\hline & & & & Ghana \\
\hline & & & & Indonesia \\
\hline & & & & Uganda \\
\hline & Constant & Togo & Burkina Faso & Philippines \\
\hline & & Zambia & $\begin{array}{l}\text { Cameroon } \\
\text { Niger }\end{array}$ & Tanzania \\
\hline & Worsening & & Kenya & Kazakhstan \\
\hline
\end{tabular}

Notes:

Countries in Italics show an unclear trend using the t-test by quintile but could be considered as experiencing a significant increase in the relative gap (see text and previous tables)

Source: Based on DHS data and previous tables 
The U5MR average reduction is mostly influenced with the reduction experimented by the middle and top social groups. Meanwhile, the reduction in child mortality for the poor has been considerable lower and in most cases not statistically different from 0 .

\section{Further considerations}

In this section we address two issues pertaining to the robustness of the results. One of them was raised earlier (section 2) and refers to the choice of indicator and whether the conclusions are retained when its "complement" is used. The second one deals with the fact that the surveys were taken at different times and the years in between them vary considerably for each country.

As Micklewright and Stewart (2000) rightly point out it is possible that the conclusions about the trends in disparity can be affected by the choice of variable. This is particularly the case when a "natural complement" exists. For instance, the "probability of surviving up to age 5 " is the complement to the variable we have used in this paper, namely the under-5 mortality rate. Leaving aside issues of definition and actual estimation of probabilities regarding whether this is an appropriate transformation of the variable or not, it might be important to investigate if the conclusions are actually affected in this case.

In 16 of the 24 cases, the same pattern, i.e. declining, constant or increasing inequality was found when we used the "probability of surviving" instead of U5MR. It is interesting to dwell on the other 8 cases. Four of them (Cameroon, Egypt, Kenya and Peru) correspond to countries where the previous analysis showed the change in disparity was not statistically significant due to the relatively small changes in the U5MR of the corresponding quintiles. Thus it could be argued that the reversed trends are not significant either. In three of the remaining cases (Bolivia, Brazil, and Ghana) it is not surprising that a reversal is found as these are countries where the quintile by quintile t-statistic resulted in unclear trends due to significant changes in both the top and bottom quintiles. Table 3 above clearly shows that an equitable path to U5MR reduction was not present in these three countries. Thus, there remains only one country, Philippines, where the results would be affected by the choice of variable.

Another issue in the analysis of these trends is that the intervals between the DHS rounds are very different from country to country. This could affect the conclusions. If changes are only significant after long periods of time, but not when surveys are separated by a few years, it is worthwhile to explore the connection between the intervening years and the statistical significance of the observed changes. Table 6 shows two stem and leaf displays. On the left, the 12 countries where no statistically 
significant changes were observed are grouped according the number of years between survey rounds. Most of them seem to be clustered around 5, although no changes are observed even after 8 or 9 years in a couple of countries. On the right, the 12 countries where statistically significant changes were observed for at least one quintile are grouped. Although some of these changes occur after 10 years, most of the surveys show statistically significant changes even in periods of only 4 or 5 years between the two rounds. Thus, it seems that the length of the period between the surveys does not undermine the conclusions regarding trends in inequality.

Table 6: $\quad$ Stem and leaf analysis of significant change in U5MR and years between rounds of the surveys

\begin{tabular}{llll}
\hline Years & No significant changes observed & Years & Significant changes observed \\
\hline 3 & I & 3 & \\
4 & II & 4 & IIII \\
5 & III & 5 & III \\
6 & II & 6 & \\
7 & II & 7 & I \\
8 & I & 8 & \\
9 & I & 9 & \\
10 & & 10 & III \\
11 & & 11 & I
\end{tabular}

\section{Immunisation}

From the information gathered by the DHS on immunisation, which covers all the antigens, we decided to concentrate the analysis of disparities and trend on DPT3 (i.e. the third inoculation of the vaccine against diphtheria, pertussis (whooping cough) and tetanus, which ought to be administered by the end of the first year of the child) because it shows access to regular immunisation services better than vaccines which require only one dose. During the 1980s great efforts were made by countries and international organisations to improve the coverage on immunisation. Because of that, at the beginning of the 1990s it is possible to find many countries with a high level of coverage.

In almost all countries, improvement of immunisation coverage continued during the 1990s, but at a slower pace. In some of them the improvement was larger than $10 \%$. The weighted average (among the countries for which we had data) went from $63.5 \%$ 
of coverage at Period 1 to $71.9 \%$ at Period 2. The following are the relevant aspects that could be highlighted.

In some countries like Bolivia, Egypt, Ghana, Kazakhstan, Mali, and Niger, the level of national average DPT3 immunisation more than doubled in roughly 10 years. In contrast, countries like Bangladesh, Burkina Faso, Cameroon, Colombia, Dominican Republic, and Philippines seem to have experienced a slight decrease in coverage. Even if this decrease is not statistically significant, it could be a warning signal of a trend towards stagnation or reversal of immunisation coverage in several countries.

The improvement in coverage encompasses the different wealth groups. Thus, the relative gap between the top and the bottom quintiles decreased for many countries (Note 15). The weighted average relative gap declined from 2.0 at the beginning of the 1990 s to 1.5 at the end. Often, the improvement for the bottom $20 \%$ has been greater than the national average.

In spite of these improvements, in many countries, only less than half of the children belonging to the bottom wealth quintile were immunised for DPT3 by the end of the 1990s. In some countries like Burkina Faso, Cameroon, Mali and Niger the coverage was near or less than $30 \%$.

The coverage in immunisation clearly moves from the top quintiles to the bottom. The poorest groups are the last ones to have access to social services, i.e. "Gaining access to basic social services can be compared with "queuing"; and the poor are often at the end of the line" (Vandemoortele, 2001).

Finally Figure 1 and Table 7 summarise the changes occurred during the 1990s. Several countries improved the level of coverage of DPT3, reducing the gap between the top and bottom quintiles. Another group showed no significant changes. Only in a few cases the situation was worse at the end of the 1990s than at the beginning. The vertical dotted line in Figure 6 represents the boundaries for statistical significance of changes in relative gap along the horizontal axis. Thus, for instance, Zambia shows a significant reduction in the gap (equity improved) while Cameroon shows a significant increase in the gap (equity worsened) and Bangladesh did not experience a significant change in the gap. Similarly, the dotted oval represents the area of no significant change in average coverage (along the vertical axis). Thus, while Egypt and Kenya show significant changes at the national level, Uganda and Burkina Faso do not. Table 7 collects this information in the matrix format used earlier for the analysis of U5MR. 
Demographic Research - Special Collection 2: Article 13

-- Determinants of Diverging Trends in Mortality --

DPT3 - Change in average and relative gap

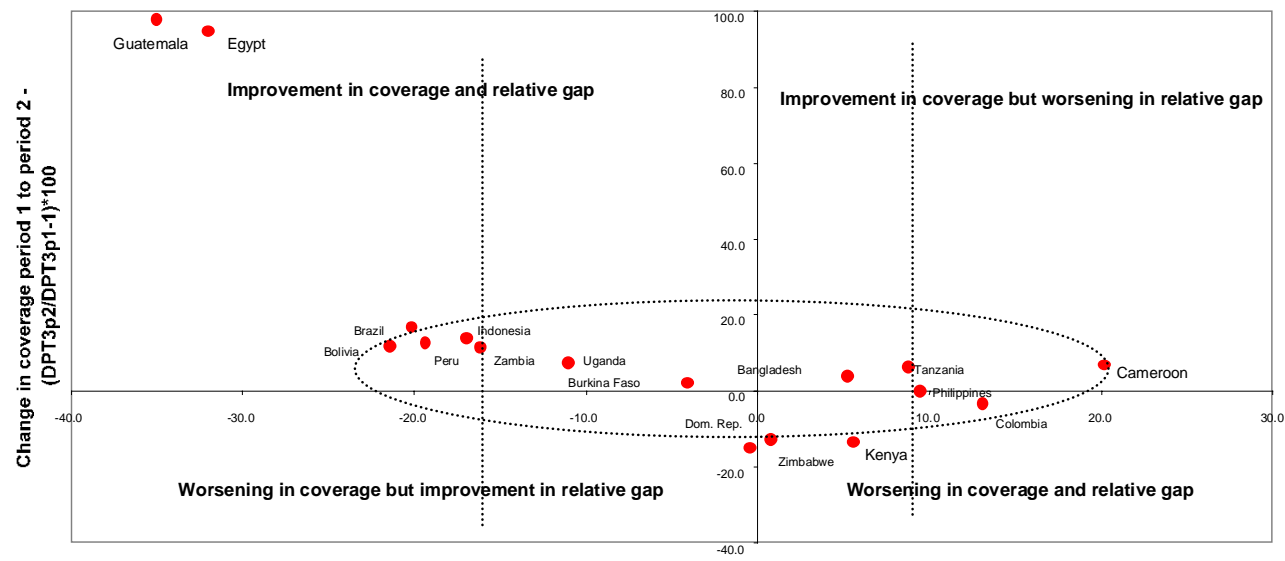

Change in relative gap from period 1 to period $2(\%)$

Notes:

The dotted lines represent a 'pseudo' confidence interval. Confidence intervals are different for each country but they have been represented by the dotted lines for graphical purposes.

Source: Based on DHS data

Figure 1: $\quad$ Confidence intervals for changes in national average and relative gap for DPT3 coverage 
Table 7: $\quad$ Changes in average DPT3 coverage and relative gap, 1980s and 1990s, selected countries.

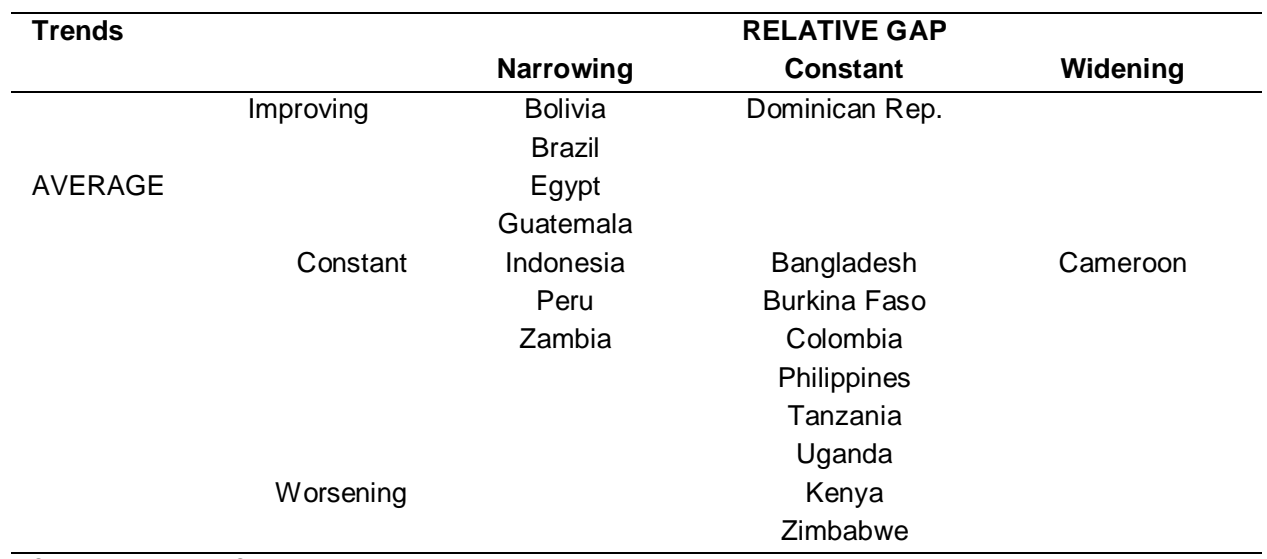

Source: Based on DHS data

Given the relatively high coverage for the better off at the beginning of the period of analysis, the increase in the average coverage is because of the improvement in the different wealth groups, especially the bottom quintile. This is different from the results regarding U5MR. For infant and child mortality, improvements among the better off were the main driver of the observed reductions in national averages.

\section{Nutrition}

Two major elements are usually considered when discussing child nutrition: micronutrients, and protein/caloric intake. Examples of the first are salt iodisation and vitamin A supplementation, for the second one underweight. In this section we concentrate on the latter.

This indicator refers to the weight of the child, given the age (weight for age). Children are compared to the established international standard and the percentage of children falling too far below (two standard deviations) from this level are considered underweight. Thus, in developing countries almost 1 in 3 children suffer from malnutrition. Moreover, this proportion has remained virtually static during the 1990s.

For the wealthiest groups, malnutrition is much less common than among the poorest households. Consequently, higher relative gaps are observed in this indicator, compared to DPT3 immunisation or U5MR. Relative gaps above 3 are very common 
and they often surpass 8 , i.e. children living in the poorest households are 8 times more likely to suffer malnutrition than better off children.

Among the 16 countries where we could compute trends in disparity, one third showed improvements in the national average. In three of these five countries (Bolivia, Colombia and Dominican Republic), the bottom quintile improved their situation faster than the better-off households. Thus, disparities were narrowed. In Ghana, the reverse is true. In Morocco, both the top and the bottom quintiles displayed statistically significant changes, and disparities remained roughly the same.

Half the countries experienced no discernible trends either at the national average level or in terms of disparities. In most of these countries, underweight did not change significantly in either the poorest or the richest households. However, in Zambia and Zimbabwe, underweight did decline for the better-off families. In Brazil, in contrast, underweight increased for the poorest ones. However, although underweight changed for some groups in these three countries, the other quintiles remained the same, stabilizing the national average. In Egypt, the substantial improvement for the bottom quintile was compensated by the decline in the top one, resulting in less inequality, but a constant national average.

Finally, there are countries where the proportion of underweight children increased. In these three cases, the worsening situation is mainly due to the deteriorating situation of the poorest households, while for the top quintile, underweight was unchanged, and thus disparities increased.

Table 8: $\quad$ Changes in average underweight (W/A -2 sd) and relative gap, 1980s and 1990s, selected countries.

\begin{tabular}{lcccc}
\hline Trends & & RELATIVE GAP & \\
& Narrowing & Constant & Widening \\
\hline \multirow{3}{*}{ AVERAGE } & Bolivia & Guatemala & Ghana \\
& & Colombia & Morocco & \\
& Cominican Rep. & & \\
& Constant & Egypt & Burkina Faso & Brazil \\
& & & Kenya & Zambia \\
& Worsening & & Peru & Zimbabwe \\
& & & & Cameroon \\
& & & & Tanzania \\
& & & & Uganda \\
\hline
\end{tabular}




\section{Some comparisons}

An interesting question now emerges: is there any relationship among these outcomes? In other words, can we combine these findings? We attempt to answer this question in this section, albeit in a very brief and preliminary manner.

First we classified countries according to the evolution of the national average in the three variables (U5MR, DPT3, and underweight). Only 19 countries were used in this exercise due to lack of data (Note 16). This resulted in four groups. Eight countries enjoyed improvements in all three variables or at least improvement in two of them and stagnation (no decline) in the other one. Six countries maintained their national averages. This includes countries were all three or two of variables were constant. It also includes a case where one of the variables was constant, one improved and the other one worsened. Two other countries suffered declines in at least two of the variables while three countries enjoyed improvements in one variable and no change in another one, but we did not have information for the third one.

For each of these four groups, we looked at the changes in the relative gap. This information is summarised in Table 9. Although this ought to be considered only as a first step in the analysis, it seems that a pattern emerges.

Table 9: $\quad$ Changes in relative gap for the three variables by country groupings based on average outcomes.

\begin{tabular}{|c|c|c|c|c|}
\hline & & U5MR gap & DPT 3 gap & Underweight gap \\
\hline First group & Bolivia & - & + & + \\
\hline \multirow[t]{7}{*}{ Average Improvement } & Brazil & - & + & + \\
\hline & Colombia & - & $\mathrm{K}$ & + \\
\hline & Dominican Rep. & - & + & + \\
\hline & Guatemala & + & + & $\mathrm{K}$ \\
\hline & Ghana & - & + & - \\
\hline & Egypt & $\mathrm{k}$ & + & + \\
\hline & Morocco & $\mathrm{k}$ & + & $\mathrm{K}$ \\
\hline Second group & Burkina Faso & $\mathrm{k}$ & $\mathrm{K}$ & $\mathrm{k}$ \\
\hline \multirow[t]{5}{*}{ Average mainly constant } & Cameroon & $\mathrm{k}$ & $\mathrm{K}$ & - \\
\hline & Peru & $\mathrm{k}$ & + & $\mathrm{K}$ \\
\hline & Tanzania & - & $\mathrm{K}$ & - \\
\hline & Uganda & - & $\mathrm{K}$ & - \\
\hline & Zambia & + & + & - \\
\hline Third group & Kenya & $\mathrm{k}$ & $\mathrm{K}$ & + \\
\hline Average decline & Zimbabwe & - & $\mathrm{K}$ & - \\
\hline Fourth group & Bangladesh & + & $\mathrm{K}$ & nd \\
\hline \multirow[t]{2}{*}{ Only two variables } & Indonesia & - & + & nd \\
\hline & Philippines & - & $\mathrm{K}$ & nd \\
\hline
\end{tabular}

Notes:

A plus sign (+) means equity improved, i.e. the gap was significantly reduced. A minus sign (-) means equity worsened, i.e. the gap was significantly increased. K means the gap was constant and nd means no data was available.

Source: Based on DHS data and previous tables 
The relative gaps improved, i.e. inequalities were reduced for at least one (and almost always both) of the determinants of U5MR in all the countries in the first group. In other words, where average outcomes were better, gaps were lower. The only exceptions occur in mortality gaps, were the results in terms of the gap are mixed. This is probably related to the queuing mentioned above.

The contrast with the other groups is interesting. For countries where outcomes have stagnated or receded, we observe either no changes in equity or worsening. This applies not only to child mortality but also to the other two variables.

\section{Conclusions}

The story that these trends tell us for these countries is clear. First, for U5MR the relative gap between the richest and poorest increased during the 1990s. Second, this uneven improvement in survival was due to the decrease of child mortality being much higher for the top quintile than for the bottom one. All too often the bottom quintile experienced no discernible improvement in U5MR.

Third, the evolution of DPT3 seems different from that of U5MR. Many countries were able to combine average increases in coverage with reductions in the relative gap.

Fourth, the picture in underweight is a bit more mixed. Almost as many countries improved their average situation while reducing disparities as the number of countries where the national average worsened and the relative gap widened.

Fifth, there seems to be a correspondence between outcomes in U5MR (in terms of the changes in the levels and relative gaps) and changes in immunisation and nutrition. Relative gaps improved for one or more of the indicators related to determinants of U5MR in many of the countries where national average trends were positive. The contrast with the countries where a more mixed (or decidedly worsening) situation prevailed is interesting. In these countries, we mostly observe either no changes in equity or higher disparities. This certainly requires further analysis, as not all countries fall into these stylised patterns.

Finally, if increases in equity combined with improvements in the national average are maintained, expanded and accelerated, then U5MR may be reduced faster and more equitably in the next 10-15 years than it has proven possible during the last decade.

\section{Acknowledgements}

This analysis is part of a broader project oriented to disparity analysis, and their trends, in relation to the goals set at the World Summit for Children. Comments from Dave 
Demographic Research - Special Collection 2: Article 13

-- Determinants of Diverging Trends in Mortality --

Gwatkin, Edilberto Loaiza and two anonymous referees as well as the assistance with calculations by Erik Bell and Garima Bal are greatly appreciated. 
Demographic Research - Special Collection 2: Article 13

-- Determinants of Diverging Trends in Mortality --

\section{Notes}

1. These countries represent about 40 per cent of the population in developing countries (excluding India and China).

2. An interesting illustration on this point is Gwatkin (2000). See also Rohde (1989).

3. There are advantages in using wealth rather than income to rank households, see for instance Minujin and Joon Hee Bang (2001). See also, Larrea (2001) and Bollen at el (1999, 2001). Cleland et al. (1992) use mother's education and father's occupation as proxies for socio-economic status.

4. Kunst (1997) and Anand et al. (2001) clearly explain many of them.

5. As Sahn and Stifel (2000) have done for some African countries.

6. Also U5MR is calculated differently in DHS reports and in the State of the World's Children, where the direct method is used. We estimated U5MR using the information on all children ever born between 10 years prior to the surveys and finding out if they were alive. This information was used to estimate the proportion/probability of dying before reaching age 5 using the life table method.

7. In terms of income, for instance, it is known that Gini coefficients of 0.6 are large, and 0.2 is low.

8. This reduction cannot be attributed to the global economic growth of the 1990s. The lack of correlation between U5MR reduction and per capita income growth is analysed in Minujin, Vandemoortele and Delamonica (2000).

9. Schneider et al. (2002) use regressions in their analysis of IMR trends in Latin America, but they apply them to countries, not the individuals.

10. We used a Cox regression as U5MR is not a variable that applies to individuals. The independent variables were: a $0-1$ dummy for the DHS round ( 0 for the first round) and a dummy for the quintiles ( 0 for the first quintile). Thus the probabilities were estimated as the difference from the probability of dying for the poorest quintile in the first round. We also introduced dummies for urban/rural location and for male/female.

11. As could be expected, given its specification. A good discussion about variables and indicators to be used for the analysis of disparity in mortality can be found in Montgomery et al (2000).

12. We assumed the variances were different in each sample, and calculated the joint variance by adding the individual ones. For this and all other tests described below, 
the significance level was set at 5 per cent. Because the DHS surveys are cluster surveys, a specific formula (provided by Macro International, the organization in charge of carrying out the DHS) is required to estimate the standard errors.

13. In this case we are constructing a new variable (the difference of the U5MRs) and estimating a new variance which results from the addition of the two estimated variances.

14. For a poignant discussion of the misguided reliance on strict application of t-tests in economics, without taking into account the "broad" picture the data present, McCloskey and Ziliak (1996) can be consulted.

15. Based on a statistical analysis similar to the one described above for U5MR.

16. We only used countries for which we had at least two of the variables. This results mainly from DHS in Asian countries usually not collecting nutrition information. 


\section{Bibliography}

Anand, S., F, Diderichsen, T. Evans, V. Shkolnikov and M. Wirth (2001) "Measuring disparities in health: methods and indicators", in Evans, T. et al. (eds.) Challenging Inequities in Health: From Ethics to Action, OUP, Oxford.

Atkinson, A. B. (1983) The Economics of Inequality, $2^{\text {nd }}$ edition, OUP, Oxford.

Bollen, K., J. Glanville and G. Stecklov (1999) "Socioeconomic Status and Class in Studies of Fertility and Health in Developing Countries", Measure Evaluation Working Paper (WP-99-13), Chapel Hill.

Bollen, K., J. Glanville and G. Stecklov (2001) "Economic Status Proxies in Studies of Fertility in Developing Countries: Does the Measure Matter?", Measure Evaluation Working Paper (WP-01-38), Chapel Hill.

Cleland, J., G. Bicego, and G. Fegan (1992) "Socioeconomic inequalities in childhood mortality: the 1970s to the 1980s", in Health Transition Review, Vol.2, No. 1.

Cornia, G. A. (1999) "Liberalization, Globalization and Income Distribution", UNU/WIDER Working Paper, Helsinki.

Filmer, D. and L. Pritchett (1998a) "Estimating Wealth Effects without Expenditure Data - or Tears: An application to educational enrolments in states of India", World Bank Working Paper, Washington D. C.

Filmer, D. and L. Pritchett (1998b) "Education Attainment of the Poor (and Rich): DHS evidence from around the globe", World Bank Working Paper, Washington D. C.

Gwatkin, D. R., S. Rustein, K. Johnson, R. Pande and A Wagstaff (1999) SocioEconomic Differences in Health, Nutrition, and Population Country Notes, Washington D. C.

Gwatkin, D. R.(2000),"Health inequalities and the health of the poor: What do we know? What can we do? in Bulletin of the World Health Organization\# 78

Kunst, A. (1997) Cross-National Comparisons of Socio-Economic Differences in Mortality, CIP, The Hague.

Larrea, C. (2001) "Salud, nutrición, e inequidad social en ocho países latinoamericanos: Un estudio comparativo a partir de las encuestas DHS", PAHO mimeo, Washington D. C. 
McCloskey, D. and T. Ziliak (1996) "The Standard Error of Regression", Journal of Economic Literature, March, 97-114.

Micklewright, J. and K. Stewart (2000) The Welfare of Europe's Children, International Research Center, Florence, UNICEF.

Minujin, A. and Joon Hee Bang (2002), "Indicadores de Inequidad Social. Acerca del uso del "indice de bienes" para la distribucion de hogares", Desarrollo Economico, Vol. 42, No. 165.

Minujin, A., J. Vandemoortele and E. Delamonica (2002) "Economic Growth, poverty and children", Environment and Urbanization, Vol 14 No 2.

Rohde Jon E.(1989), Disparity reduction. A Strategy for Children in the 1990s, UNICEF Background Document \#24

Sahn, D., D. Stifel, and S. Younger et al (1999) "Intertemporal Changes in Welfare: preliminary results for 9 African countries", Working Paper 94, Center for Food and Nutrition Policy, Cornell University, Ithaca.

Sahn, D., and D. Stifel (2000) "Poverty comparisons over time and across countries", Word Development, Vol 28.

Schneider, M., C. Castillo-Salgado, E. Loyola-Elizondo, J. Bacallao, O. Mujica, M. Vidaurre, and G. Alleyne (2002) "Trends in infant mortality inequalities in the Americas", Journal of Epidemiology and Community Health, vol. 56.

Sen, A. (1997) On Economic Inequality, $2^{\text {nd }}$ edition, Clarendon, Oxford.

Stecklov, G., A. Bommier, and T. Boerma (1999) "Trends in equity in Child Survival in Developing Countries: An illustrative analysis using Ugandan data“, mimeo, Carolina Population Center, Chapel Hill.

Vandemoortele (2001) Absorbing Social Shocks, Protecting Children and Reducing Poverty; The role of basic social services, UNICEF Staff Working Papers, Evaluation, Policy and Planning series number 00-001, UNICEF, New York. 


\section{Annex: Indicators used to calculate the wealth index}

Although the questions vary slightly from country to country, the most common indicators of the assets used to calculate the wealth index are:

Source of drinking water

Type of toilet facility

Type of roof material

Type of floor material

Availability of electricity

Availability of radio

Availability of television

Availability of refrigerator 